\title{
Where Should Hospitalists Sit Within the Academic Medical Center?
}

\author{
Scott A. Flanders, $M D^{7}$, Sanjay Saint, $M D, M P H^{1,2}$, Laurence F. McMahon, MD, $M P H^{7}$, \\ and Joel D. Howell, MD, PhD
}

'Department of Internal Medicine, University of Michigan Medical School, Ann Arbor, MI, USA; ${ }^{2}$ Ann Arbor VA Medical Center, Ann Arbor, MI, USA.

One of the most significant changes in US hospitals over the past decade has been the emergence of hospitalists as key providers of inpatient care. The number of hospitalists in both community and teaching hospitals is growing rapidly, and as the field burgeons, many are questioning where hospitalists should reside within the academic medical center (AMC). Should they be a distinct division or department, or should they be incorporated into existing divisions? We describe hospital medicine's current trajectory and provide recommendations for hospital medicine's place in the AMC. Local social and economic factors are most likely to determine whether hospital medicine programs will become independent divisions at most AMCs. We believe that in many large AMCs, separate divisions of hospital medicine are less likely to form soon, and in our opinion should not form until they are able to fulfill the tripartite mission traditionally carried out by independent specialist divisions. At community hospitals and less research-oriented AMCs, hospital medicine programs may soon be ready to become separate divisions.

$\mathrm{J}$ Gen Intern Med 23(8):1269-72

DOI: $10.1007 / \mathrm{s} 11606-008-0682-1$

(c) Society of General Internal Medicine 2008

\section{INTRODUCTION}

Hospitalist physicians, usually general internists, have recently become key providers of inpatient care. ${ }^{1,2}$ Reasons for this change include improved hospital care efficiency, physician ownership of inpatient quality initiatives, and the challenges of managing patients in both the office and hospital. Teaching hospitals also employ hospitalists to mitigate pressures resulting from resident work hour reductions. There are over 15,000 hospitalists in the US, with numbers expected to double by 2010 (Fig. 1). Nearly 30\% of US hospitals have hospital medicine groups, including over $60 \%$ for hospitals with $>200$ beds. $^{3}$ Among academic medical centers (AMCs), over half of teaching hospitals and $66 \%$ of major teaching hospitals (defined as a member of the Council of Teaching Hospitals and Health Systems) have hospital medicine groups. ${ }^{3}$ These tend to be

Received February 8, 2008

Revised April 18, 2008

Accepted April 18, 2008

Published online July 1, 2008 quite large, averaging 17 hospitalists per program. ${ }^{3}$ While some of these hospitalists may be recent graduates of residency programs wishing to hone their clinical skills before pursuing subspecialty fellowship training, our focus is on those physicians who are pursuing a career in hospital medicine. We ask: Where should hospitalist programs sit within the AMC structure? Should hospitalists hold appointments within an existing internal medicine division? If so, which one? Or, should separate divisions of hospital medicine be created?

\section{CURRENT ROLES OF HOSPITAL MEDICINE GROUPS}

The hospitalist's primary task remains day-to-day clinical care of complex medical patients. Most evidence supports the premise that a hospitalist model is more efficient in caring for hospitalized patients. ${ }^{4-6}$ While some studies have also suggested that hospitalists may improve the quality of care, this has been an inconsistent finding. ${ }^{4,5,7,8}$ Some hospitalists have established palliative care programs, quality improvement and patient safety programs, and surgical co-management programs. ${ }^{2,9-12}$ In addition, hospitalists are often involved in administrative roles.

Teaching hospitals support residency programs. Faced with increased educational oversight and Medicare billing requirements, AMCs have increasingly staffed resident teaching services with hospitalists and have found that they are more highly rated on teaching evaluations when compared to nonhospitalist inpatient ward attendings. ${ }^{13,14}$

In July 2003 the Residency Review Committee (RRC) began enforcing rules that limited residents' work hours. ${ }^{15}$ Faced with increasing bed occupancy, increasingly complex patient populations, and the perception that the floats, hand-offs, and patchwork coverage solutions to work hour restrictions were adversely affecting patient care, ${ }^{16-18}$ many AMCs chose to move patients from resident services onto non-resident services, which were commonly staffed by hospitalists. ${ }^{19,20}$

Research is an essential role for medical school faculty, yet research performed by hospitalists has been slow to develop. Early in the development of hospitalist programs, research focused on studying the hospitalist model itself. Newer research examines the clinical approach to hospitalized patients, implementation of best practices, care transitions, and how to improve patient safety. While a few hospital medicine programs have successfully recruited well-trained researchers, competed for extramural funding, and developed a clinical research infrastructure, these remain the exception rather than the rule. $^{21}$ 


\section{Growth of Hospital Medicine}

Hospitalists in North America

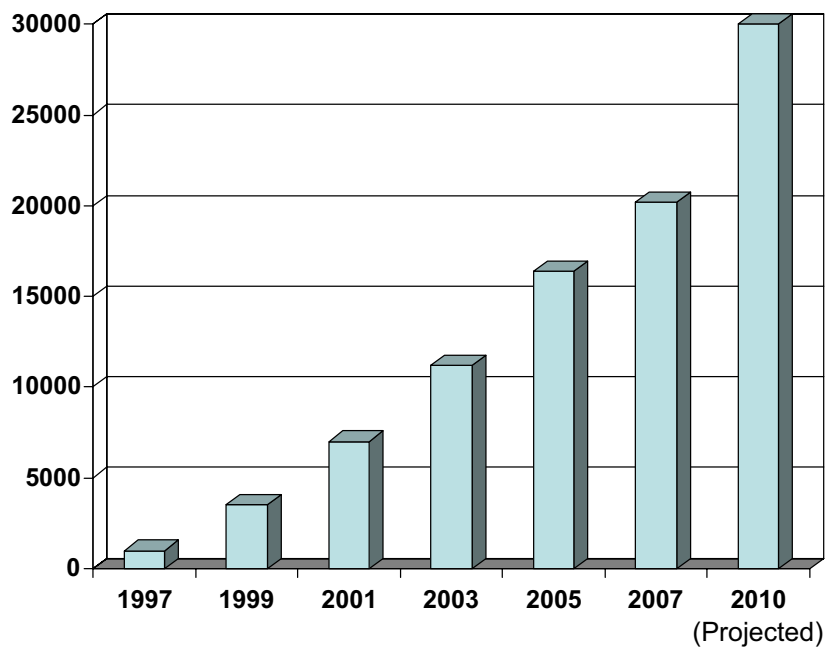

Data from the Society of Hospital Medicine (with permission)

\section{Number of Hospitalists}

Figure 1. Growth of hospital medicine. Source: Society of Hospital Medicine.

Although the paucity of robust research groups is often attributed to the field's youth, it may also reflect disagreement as to just what hospitalists should study. The structure of most hospitalist programs may not allow hospitalists sufficient time to focus on research. Moreover, funding from the National Institutes of Health (NIH) is difficult to obtain for hospitalist research. Like researchers in any new field, hospitalists need substantial institutional investment in their research. The investment will likely need to come not only from departments of internal medicine, but also from the medical school and the hospital. While found at a handful of academic medical centers, such organizational investment in hospitalist research remains uncommon. In addition, the underdevelopment of hospital medicine research almost certainly reflects a lack of robust hospitalist research training programs.

\section{HOSPITALIST TRAINING PROGRAMS}

Hospitalists' diverse clinical backgrounds may help explain the paucity of hospitalist training programs and the lack of formalized requirements for hospitalist practice. About 3\% are family physicians and another $11 \%$ are pediatricians. ${ }^{22}$ In addition, some obstetricians only work shifts on the hospital's labor and delivery wards (laborists), and, increasingly, some surgeons have elected a career as surgical hospitalists. ${ }^{23,24}$

However, most hospitalists are, and are likely to remain, general internists. A handful of internal medicine residency programs have begun experimenting with hospitalist residency tracks. ${ }^{25,26}$ A few AMCs have developed hospitalist fellowships to provide advanced training in research methods, medical education, and quality improvement and management. However, there are now only 16 active hospitalist fellowships, 10 in internal medicine, 4 in pediatrics, and 2 in family practice. ${ }^{27}$ Training in research skills could also be obtained in a range of fellowship programs such as the Robert Wood Johnson Clinical Scholars program. Development of hospitalist training programs would likely accelerate hospital medicine research by creating a cadre of faculty capable of high-quality research and might lead to more hospital medicine groups with a portfolio of core activities (clinical work, teaching, research, training programs) that are similar to other established divisions in the academic medical center.

\section{CURRENT STRUCTURE OF HOSPITAL MEDICINE PROGRAMS}

Most AMC hospitalist programs are in departments of internal medicine. Because many initial hospitalists focused on the inpatient care of general medical patients, it seemed logical that their appointments would be within divisions of general internal medicine. As these programs expanded, a hospitalist director - usually a general internist - was hired to run the program. However, there was significant heterogeneity among the early programs. Some medical centers, such as the University of California at Davis, hired hospitalists into the division of pulmonary and critical care medicine. A few, such as University of California at San Francisco, University of California at San Diego, University of Massachusetts, Ohio State University, and Northwestern University, established independent or quasi-independent divisions of hospital medicine within internal medicine. The forces driving the creation of separate hospital medicine divisions in AMCs vary. In at least one case, the perception of a differing culture between the hospital medicine group and the remainder of the general medicine division combined with the large administrative burden associated with the hospitalist program and a dramatically different financial infrastructure led to the creation of the new hospital medicine division. (Personal communication: Greg Maynard, Joe Ramsdell; April, 2007)

\section{OPTIONS FOR THE FUTURE}

Now that hospitalist programs are well established in AMCs, it is important to raise a key question: Where in the academic infrastructure should they be located? If seated in internal medicine (and most are), should hospitalist programs be one element of a division of general medicine, or should they become a separate division? Most internal medicine divisions at major AMCs are focused on a tripartite mission of clinical care, teaching, and research. Most succeed (or at least aspire to succeed) in all three domains. ${ }^{28}$ However, at smaller academic centers, or at community teaching hospitals, the departmental and divisional structure may be driven less by research and more by teaching, faculty size, clinical volume, or less tangible variables, such as institutional prominence.

Because most AMC hospital medicine groups were borne of clinical and educational needs, most new hospitalist faculty members were hired directly out of residency (or chief residency) and lacked formal research training. They were extremely busy performing clinical duties and generally lacked effective mentors. When they did attempt research, hospitalist faculty tended to work in areas such as quality improvement and educational evaluation that lacked robust federal sources for extramural support. Finding themselves within divisions of general internal 
medicine, as most did, some hospitalists were able to tap into existing clinical and teaching programs, and some benefited from a research infrastructure and senior faculty mentors who knew how to succeed in academics. For these important reasons, many hospitalist programs have thrived within divisions of general internal medicine.

Should they continue to do so? Or should they become separate divisions?" The answer depends in large part on divisional and departmental culture. Divisions may lack cohesion when faculty members have markedly differing job descriptions, practice locales, and worldviews. General medicine divisions that continue to see hospital practice as a central mission will be better able to embrace hospitalists than those who view themselves as predominately primary care divisions. Concerning faculty practice in both the inpatient and outpatient settings, creating a separate division of hospital medicine would call into question where these faculty members should reside. However, few faculty are actually split $50 / 50$. Faculty could migrate to a "core division" or academic home, but continue to easily practice in both environments. Similarly, should subspecialty services choose to use hospitalists, the academic home for these faculty would largely be determined by their training and scope of practice. A boardcertified gastroenterologist hired to manage inpatients with primarily gastrointestinal issues should reside in the gastroenterology division, while an internist with no subspecialty training hired to manage patients on an inpatient cardiology service should reside within the hospital medicine division.

At research-intensive AMCs, most formally constituted divisions have well-defined intellectual domains, training programs, and vigorous research programs. At present, most hospitalist programs would not meet these criteria. Until all these elements exist within a hospital medicine group, hospitalist faculty may be better served within an established division. Prematurely creating a hospitalist division risks separating faculty from resources that might otherwise facilitate academic accomplishments and career advancement. If a newly created hospital medicine division was perceived as obviously deficient in one or more of the key components of a successful academic division, it might be harder pressed to obtain the resources and support critical to a division's academic success. On the other hand, being able to "sit at the table" with other division chiefs may improve hospitalists' visibility and access to important organizational opportunities (Table 1).

At smaller teaching hospitals, however, the organizational principles are more likely to be dominated by clinical volume, teaching roles, financial considerations, and institutional prominence. Should hospitalist programs there meet the local core criteria, there is no obvious reason not to create a separate hospital medicine division (or perhaps even department).

Hospitalist programs may face challenges that are sufficiently different from other clinical programs to justify or require programmatic autonomy. Many hospitalist programs must adapt to rapidly changing circumstances. A growing inpatient census or new workforce requirements may oblige programs to recruit new faculty rapidly or swiftly change how hospitalized patients are managed based on quality or safety needs. A hospitalist program may thus need to develop structures and processes that are quite different from those of other divisions, including the hospitalists' current division. If an existing organizational structure creates barriers that impede the ability of hospitalist groups to react quickly to a changing environment, it may be sensible to create a separate division or department.

The American Board of Internal Medicine (ABIM) may create a new status that would be obtained through the ABIM's maintenance of certification process, called "recognition of focused practice in hospital medicine." This recognition will likely require time in hospitalist practice, documentation of volume thresholds for common inpatient diagnoses, and successful completion of a secure exam. But unlike board certification in most specialties, "focused recognition" as currently envisioned will not require additional fellowship training in the field of hospital medicine. If this quasi "board certification" for hospitalists becomes a reality (and is perceived to be valuable), it might encourage the creation of separate divisions, particularly if hospitalists perceive increasing dissimilarity in their professional duties from that of their outpatient general internal medicine colleagues.

This certification could highlight the need for more robust hospitalist training programs. For example, if focused recognition revealed that many hospitalists were not proficient in endof-life care, quality improvement, medical consultation, or other content areas not traditionally well-covered in internal medicine residency training programs, one solution could be to develop a hospitalist residency track or a fellowship that better taught these skills. ${ }^{26}$

However, certification in other areas has not always resulted in a uniform organizational structure. For example, geriatrics offers an added "certificate," yet it has a mixed organizational history - in some AMCs it is an independent division, in others it remains part of general medicine. Local culture often drives organizational structure.

Table 1. Potential Advantages and Disadvantages of the Creation of a Separate Division of Hospital Medicine

\begin{tabular}{ll}
\hline \hline Potential advantages & Potential disadvantages \\
\hline Distinct group with similar mission, culture, and "world view" & $\begin{array}{c}\text { Seclusion, loss of "power in numbers," lack of exposure to other } \\
\text { world viewpoints } \\
\text { Loss of negotiating power if not part of a bigger more established division } \\
\text { Increased autonomy and financial independence }\end{array}$ \\
$\begin{array}{l}\text { Increased visibility/prestige } \\
\text { Program has a seat at the hospital and departmental leadership } \\
\text { tables }\end{array}$ & $\begin{array}{l}\text { Potential loss of access to financial resources } \\
\text { Division chief of hospital medicine might enjoy more discretionary } \\
\text { resources }\end{array}$ \\
$\begin{array}{l}\text { Research faculty more focused on hospital issues } \\
\text { At least on the totem pole }\end{array}$ & $\begin{array}{l}\text { Few senior division faculty for mentoring } \\
\text { Low rank on divisional totem pole/hierarchy, relegated to "second class" } \\
\text { status }\end{array}$ \\
\hline
\end{tabular}


Organizations work best with superb leaders. Most division chiefs are senior faculty who have succeeded in the clinical, educational, and research realms. The excellent ones understand AMC organization, know how to obtain resources, and can successfully mentor junior faculty. However, many hospitalist programs are led by recent graduates of residency training programs who lack an academic track record. These individuals may be less adept at mentoring junior faculty and successfully negotiating within the AMC. However, some potential hospitalist program directors may see separate divisional status as a necessary condition for taking on the responsibility. Institutions with a more senior and experienced hospitalist program leader will be more successful in creating a separate division of hospital medicine.

Hospital medicine groups are rapidly growing to the point that they may soon be as large as many other independent divisions, or even departments. As superficially appealing as such status may appear, hospitalists and AMC leaders throughout the United States need to think carefully about whether hospitalist programs should exist as a distinct division. We feel that in most research-intensive AMCs, separate divisions of hospital medicine should not form until they are able to fulfill the tripartite mission traditionally carried out by independent specialist divisions, which in most cases is unlikely to be soon. At community hospitals (or less research-oriented AMCs), the organizing principles of divisions are less likely to include a strong emphasis on research, and many hospitalist groups may be ready to become separate divisions. In either scenario, it is critical that the decision is strategic, not expedient. The creation of a new division in internal medicine or department should advance the mission(s) of the organization and the associated faculty and not be motivated by a "quick judgment" related to recruiting a hospitalist director or mitigating the perceived administrative burden of an existing division. Ultimately, the best course will depend on local circumstances, and as long-time Speaker of the House Tip O'Neil once said, "All politics is local."

Acknowledgements: Dr. Saint is supported by an Advanced Career Development Award from the Health Services Research and Development Program of the Department of Veterans Affairs. We are indebted to Robert M. Wachter, MD, for reviewing an earlier draft of this manuscript and to Amy J. Markowitz, JD, for editorial assistance.

Conflict of Interest Statement: All authors have reviewed the manuscript and have approved the final version as submitted. No potential conflicts of interest exist in connection with this article.

Corresponding Author: Scott A. Flanders, MD; University of Michigan, 3119F Taubman Center, 1500 E. Medical Center Dr., Ann Arbor, MI 48109, USA (e-mail: flanders@umich.edu).

\section{REFERENCES}

1. Wachter RM, Goldman L. The emerging role of "hospitalists" in the American health care system. N Engl J Med. 1996;335:514-7.
2. Lindenauer PK, Pantilat SZ, Katz PP, Wachter RM. Hospitalists and the practice of inpatient medicine: results of a survey of the National Association of Inpatient Physicians. Ann Intern Med. 1999;130:343-9.

3. Kralovec PD, Miller JA, Wellikson L, Huddleton JM. The Status of Hospital Medicine Groups in the United States. Journal of Hospital Medicine. 2006;1:75-80.

4. Coffman J, Rundall TG. The impact of hospitalists on the cost and quality of inpatient care in the United States: a research synthesis. Med Care Res Rev. 2005;62:379-406.

5. Wachter RM, Goldman L. The hospitalist movement 5 years later. JAMA. 2002;287:487-94

6. Lindenauer PK, Rothberg MB, Pekow PS, Kenwood C, Benjamin EM, Auerbach AD. Outcomes of care by hospitalists, general internists, and family physicians. N Engl J Med. 2007;357:2589-600.

7. Meltzer DOSM, Morrison J. Decreased length of stay, costs, and mortality in a randomized trial of academic hospitalists. J Gen Intern Med. 2001;16supplS208.

8. Auerbach AD, Wachter RM, Katz P, Showstack J, Baron RB, Goldman L. Implementation of a voluntary hospitalist service at a community teaching hospital: improved clinical efficiency and patient outcomes. Ann Intern Med. 2002;137:859-65.

9. Pantilat SZ. End-of-life care for the hospitalized patient. Med Clin North Am. 2002;86:749-70. viii.

10. Pantilat SZ, Rabow MW, Citko J, von Gunten CF, Auerbach AD, Ferris FD. Evaluating the California Hospital Initiative in Palliative Services. Arch Intern Med. 2006;166:227-30.

11. Huddleston $\mathbf{J}$ LD, Vanness $\mathbf{D}$, et al. Partnering for optimal patient care: Prospective, randomized, controlled trial of the inpatient experience of a hospitalist-orthopedic team. Annual Meeting of the National Association of Inpatient Physicians, Philadelphia, PA 2002.

12. Hoff TH, Whitcomb WF, Williams $\mathbf{K}$, Nelson JR, Cheesman RA. Characteristics and work experiences of hospitalists in the United States. Arch Intern Med. 2001;161:851-8.

13. Hauer KE, Wachter RM, McCulloch CE, Woo GA, Auerbach AD. Effects of hospitalist attending physicians on trainee satisfaction with teaching and with internal medicine rotations. Arch Intern Med. 2004; 164:1866-71.

14. Kripalani S, Pope AC, Rask K, et al. Hospitalists as teachers. J Gen Intern Med. 2004; 19:8-15.

15. Philibert I, Friedmann P, Williams WT. New requirements for resident duty hours. JAMA. 2002;288:1112-4.

16. Arora V, Johnson J. A model for building a standardized hand-off protocol. Jt Comm J Qual Patient Saf. 2006;32:646-55.

17. Arora V, Johnson J, Lovinger D, Humphrey HJ, Meltzer Do. Communication failures in patient sign-out and suggestions for improvement: a critical incident analysis. Qual Saf Health Care. 2005; 14:401-7.

18. Horwitz LI, Krumholz HM, Green ML, Huot SJ. Transfers of patient care between house staff on internal medicine wards: a national survey. Arch Intern Med. 2006;166:1173-7.

19. Saint S, Flanders SA. Hospitalists in teaching hospitals: opportunities but not without danger. J Gen Intern Med. 2004;19:392-3.

20. Fitzgibbons JP, Bordley DR, Berkowitz LR, Miller BW, Henderson MC. Redesigning residency education in internal medicine: a position paper from the Association of Program Directors in Internal Medicine. Ann Intern Med. 2006;144:920-6.

21. Flanders SA, Kaufman SR, Saint S. Hospitalists as emerging leaders in patient safety: Targeting a few to affect many. Journal of Patient Safety. $2005 ; 1: 78-82$.

22. Hospital Medicine Survey. Society of Hospital Medicine, 2007. (Accessed Last Accessed 4/24/08, at http://www.hospitalmedicine.org/Content/ NavigationMenu/Media/MediaKit/Media_Kit.htm.)

23. Castellanos P. The laryngology hospitalist. J Voice. 2005; 19:470-5.

24. Weinstein $\mathbf{L}$. The laborist: a new focus of practice for the obstetrician. Am J Obstet Gynecol. 2003;188:310-2.

25. Hauer KE, Flanders SA, Wachter RM. Training future hospitalists. West J Med. 1999;171:367-70.

26. Plauth WH 3rd, Pantilat SZ, Wachter RM, Fenton CL. Hospitalists' perceptions of their residency training needs: results of a national survey. Am J Med. 2001;111:247-54.

27. Ranji SR, Rosenman DJ, Amin AN, Kripalani S. Hospital medicine fellowships: works in progress. Am J Med. 2006;11972e1-7.

28. Braunwald E. Departments, divisions and centers in the evolution of medical schools. Am J Med. 2006;119:457-62. 